\title{
Ex Situ Conservation of Vegetatively Propagated Species: Development of a Seed-based Core Collection for Malus sieversii
}

\author{
Gayle M. Volk'1, Christopher M. Richards, Ann A. Reilley, and Adam D. Henk \\ National Center for Genetic Resources Preservation, U.S. Department of Agriculture, 1111 S. Mason \\ Street, Fort Collins, CO 80521 \\ Philip L. Forsline \\ Plant Genetic Resources Unit, U.S. Department of Agriculture, Geneva, NY 14456-0462
}

\author{
Herb S. Aldwinckle \\ Department of Plant Pathology, Cornell University, Geneva, NY 14456-0462
}

\begin{abstract}
AdDitional INDEX WORDs. apple, Malus, simple sequence repeat, genetic diversity
Abstract. Seeds and scionwood of Malus sieversii Lebed. have been collected from wild populations of apple trees in Kazakhstan. Seedlings and grafted trees were planted in the orchards at the U.S. Dept. of Agriculture Plant Genetic Resources Unit in Geneva, N.Y. We developed core collections to capture the genetic and phenotypic diversity represented in the trees from each of two of the Kazakhstan collection sites. These core collections capture more than $90 \%$ of the genetic diversity of the original populations, as determined using seven unlinked simple sequence repeat markers and 19 quantitative traits. Since phenotypic evaluations of these materials have been completed, the 35 trees within each population will be used as parents in crosses so that the genetic diversity in the orchard populations can be captured as seed for long-term ex situ conservation. This strategy of storing seeds, rather than maintaining costly field collections, could be applied to other collections of wild plant materials in the National Plant Germplasm System.
\end{abstract}

Malus sieversii, the main progenitor of the domesticated apple (Malus $\times$ domestica Borkh.), is endemic to the Republic of Kazakhstan (Harris et al., 2002; Hokanson et al., 1997; Luby et al., 2001). U.S. Dept. of Agriculture (USDA)-sponsored plant exploration teams have visited Kazakhstan to collect wild apple germplasm in 1989, 1993, 1995, and 1996. More than 130,000 seeds were collected from a total of 892 wild $M$. sieversii trees. Scionwood was also collected from 43 trees across 12 locations that displayed desirable horticultural characteristics (Luby et al., 2001).

Between 10 and 20 open-pollinated seeds of each tree from which seeds were collected were planted at the USDA Plant Genetic Resources Unit (PGRU) in Geneva, N.Y. Detailed phenotypic evaluations have been completed on the seedlings from two sampling sites (6 and 9) from the 1995 and 1996 trips (Fig. 1). Seedlings have been identified with resistance to apple scab (Venturia inaequalis Cooke), fire blight (Erwinia amylovora Burrill), and cedar apple rust (Gymnosporangium juniperi-virginianae Schwein), as well as characteristics such as large and flavorful fruit (Forsline and Aldwinckle, 2004).

Molecular methods were used to evaluate diversity within several Malus L. collections. Simple sequence repeats (SSRs) are an effective molecular technique for fingerprinting individual Malus $\times$ domestica varieties. Many of the described SSR loci have numerous alleles in $M . \times$ domestica, so allelic diversity can be described using fewer than 10 primer pairs (Hokanson et al.,

Received for publication 18 June 2004. Accepted for Publication 24 Aug. 2004. Mention of trade names or commercial products in this article is solely for the purpose of providing specific information and does not imply recommendation or endorsement by the U.S. Dept. of Agriculture.

${ }^{1}$ Corresponding author; e-mail: gvolk@lamar.colostate.edu
1998, 2001). Representative core collections have been developed using molecular techniques for USDANational Plant Germplasm System (NPGS) collections of Malus and Vitis L. (Hokanson et al., 1998, 2001; Lamboy and Alpha, 1998).

It is both expensive and risky to maintain wild seedling populations in the field indefinitely. Many of the trees are susceptible to diseases such as apple scab and fire blight. Since phenotypic characterizations under field conditions have been completed, the $M$. sieversii collection can be stored as seeds at $-20^{\circ} \mathrm{C}$ for future use.

This paper describes the assembly of a genetically representative set of seedling trees from 43 half-sib families from two

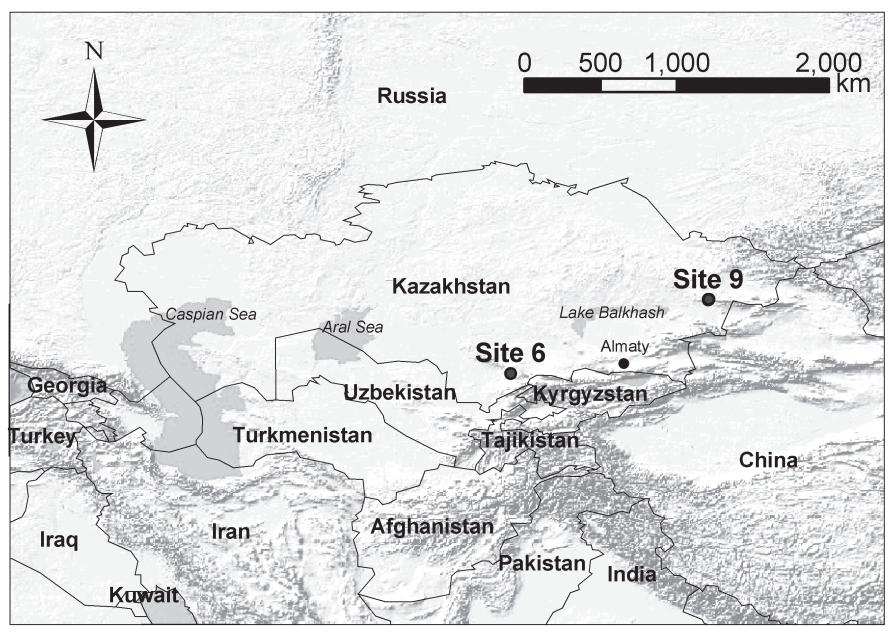

Fig. 1. Central Asia map shows the Kazakhstan site 6 and site 9 M. sieversii collection sites. 
locations in Kazakhstan that were previously uncharacterized. Core collections representing these populations were identified using both phenotypic and genotypic data. These core collections represent more than $95 \%$ of the alleles present in the seedling populations and allow the curator to effectively capture the genetic diversity of these populations by performing directed crosses in the field.

\section{Materials and Methods}

Plant material. Malus sieversii plant materials were collected from 12 sites within Kazakhstan during exploration visits in 1989, 1993, 1995, and 1996. Seeds and scionwood from two of these sites, designated 6 and 9, were included in the present study (Fig. 1). Collectors at site 6 gathered seeds from trees along a stream (site $6.00 ; 600$ m elevation) and in a xeric mixed scrub forest (site 6.01; 900 m elevation) in the Karatau Mountains (Fig. 2A). Overall, this dry region contained highly aromatic and firm fruit (Forsline et al., 2003, Luby et al., 2001). Seedlings from 14 half-sib families from site 6 were included in this study.

Seeds and scionwood were collected from 6 sub-sites $(9.00$ 9.05) within the Semipalitinsk region of the Tarbagatai mountain range (Fig. 2B) in 1995 and 1996. Seedlings from 29 half-sib families and 12 grafted trees from scionwood from site 9 were included in this study. This dry continental forest is located 20 $\mathrm{km}$ north of Urdzhar and 3 to $5 \mathrm{~km} \mathrm{NE}$ of Alexseyevka covering an area of $3.5 \times 3 \mathrm{~km}$. This region receives $400 \mathrm{~mm}$ of annual rainfall and has temperatures that range from +40 to $-40^{\circ} \mathrm{C}$. The sub-sites within site 9 varied with respect to elevation (870 to $1120 \mathrm{~m}$ ), environment (streamside vs. hillside), and tree density. Detailed site descriptions are presented by Dzhangaliev (2003) and Forsline et al. (2003).

Phenotypic characterization. Seedling trees produced from seeds collected from the 1995 and 1996 Kazakhstan expeditions were transplanted to an orchard setting (1997 for those collected in 1995, and 1998 for those collected in 1996) where disease resistance and fruit phenotypes were described for a collection of fruit-bearing seedling trees from each original half-sib family. Phenotypic characters included fire blight resistance, scab resistance, fruit flesh color, firmness, flavor, oxidation, juiciness, weight, shape texture, soluble solids percentage, fruit shape uniformity, fruit size uniformity, and harvest season. In addition, data were collected on fruit for ground color (base color), overcolor (color overlaying the base color), overcolor pattern and intensity, as well as russeting location, type, and coverage. All phenotypic characters were converted to categorical variables based on categories described in the Germplasm Resources Information Network (GRIN). Data were collected as described by Forsline and Aldwinckle (2004) and are available online (U.S. Dept. of Agriculture, 2004).

Molecular analysis. Genomic DNA from leaf tissue of 439 individual $M$. sierversii seedlings was extracted using DNeasy 96 plant kits (Qiagen, Valencia, Calif.). Two samples from each individual were collected and processed independently. Malus single sequence repeats (SSR) were amplified using unlinked primers (GD12, GD15, GD96, GD100, GD103, GD142, GD147, GD162) as described by Hokanson et al. (1998) and Hemmat et al. (2003). Forward primers, labeled with either IRD 700 or IRD 800, were obtained from MWG-Biotech (High Point, N.C.). Unlabeled reverse primers were purchased from IDT (Coralville, Iowa).

All polymerase chain reactions (PCR) were carried out in 15 $\mu \mathrm{L}$ total volume. For each reaction, 10 to $50 \mathrm{ng}$ DNA template
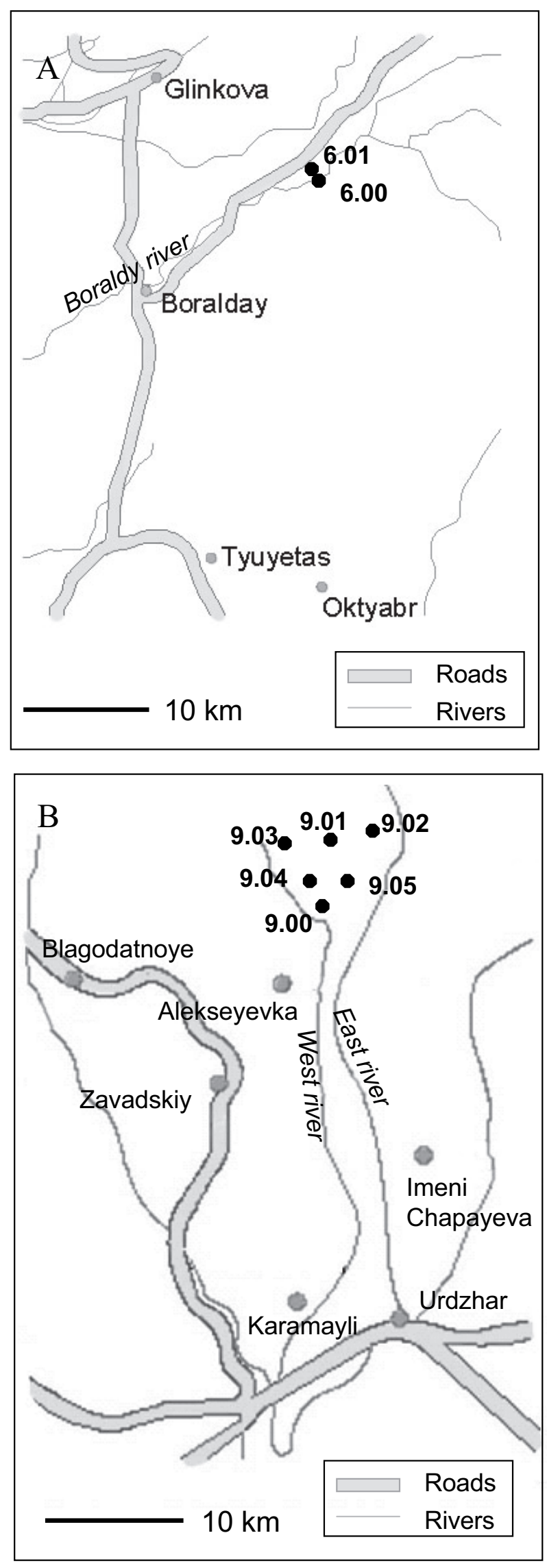

Fig. 2. M. sieversii accessions were collected from sites $6(\mathbf{A})$ and $9(\mathbf{B})$ in Kazakhstan. 
and primers ( 0.3 to $0.7 \mathrm{pm})$ were combined with 1.5 units Taq Polymerase (Promega, Madison,Wis.), $1 \times$ Promega Magnesium free buffer (10 mM Tris-HCl, $50 \mathrm{~mm} \mathrm{KCl}$ and $0.1 \%$ Triton X-100), $0.25 \mathrm{~mm} \mathrm{MgCl}_{2}$, and $0.25 \mathrm{~mm}$ dNTP.

PCR amplifications were carried out using MJ Research (Reno, Nev.) PTC 200 or Dyad Thermocyclers. A touch-down program reduced the annealing temperature $2^{\circ}$ every other cycle starting at $63{ }^{\circ} \mathrm{C}$ and ending at $57^{\circ} \mathrm{C}$, followed by an annealing temperature of $55^{\circ} \mathrm{C}$ for 20 additional cycles, and ended with a 2-min $72{ }^{\circ} \mathrm{C}$ extension. Completed PCR reactions were diluted 1:1 in $95 \%$ formamide, $50 \mathrm{~mm}$ EDTA, bromophenol blue loading dye, and denatured at $95{ }^{\circ} \mathrm{C}$ for $3 \mathrm{~min}$. Gels (6.5\% LI-COR KB Plus acrylamide; LI-COR, Lincoln, Nebr.) were run in $1 \times \mathrm{TBE}$ (89 mm Tris, $89 \mathrm{~mm}$ boric acid, $20 \mathrm{~mm}$ EDTA) buffer for $1 \mathrm{~h} 45$ min at $1500 \mathrm{~V}, 40 \mathrm{~W}, 40 \mathrm{~mA}$, and $45^{\circ} \mathrm{C}$ on a LI-COR 4200 DNA Sequencer. Digital images were collected from the sequencer using LI-COR Saga Generation2 software and were manually analyzed using the Saga software. Alleles from replicate samples were examined at each locus, and when alleles for replicates were not identical, data for that locus were entered as "missing" in subsequent analysis.

Genetic ANALYSIS AND DEVELOPMENT OF CORE COLLECTIONS. Genotypic data were initially analyzed for several descriptive measures of genetic diversity and divergence such as genetic differentiation $\left(\mathrm{F}_{\mathrm{st}}\right)$, allelic richness, and gene diversity. Genetic analyses and significance testing were carried out using both GDA (Lewis and Zaykin, 2001) and FSTAT (Goudet, 1995).

Core collections were assembled for each sampling site using the maximization strategy outlined by Schoen and Brown (1995), and were implemented in the software package MSTRAT (Gouesnard et al., 2001). The MSTRAT algorithm maximizes the total number of alleles collected in a target core using equally weighted genotypic and phenotypic data. Genetic redundancy among individuals was examined using a feature of MSTRAT that plots samples of increasing sizes maximized for diversity against the amount of total diversity captured. If there is no redundancy and each individual contributes novel genetic diversity, an increase in core size is linearly related to an increase in core diversity. However, genetic redundancy is reflected by a curvilinear relationship where above some size class, further increases in sample sizes do not substantially increase the fraction of total diversity captured. These plots can be viewed as a saturation curve where the inflection point represents a minimum size of a core collection. Collections that are largely redundant saturate earlier (and require a small core size to capture most of the diversity) than collections that are not redundant. For each site, 10 alternative core collections with nearly equivalent maximal genetic diversity were assembled in MSTRAT by iteratively sampling individuals and evaluating their contribution to allelic diversity. A single core group was selected by choosing the core collection that represented the greatest number of half-sib populations and displayed the highest number of accessions with disease resistance characteristics.

\section{Results}

DNA was extracted from $174 \mathrm{M}$. sieversii seedlings from site 6 , and 278 seedlings and trees grafted from scions from site 9 (Table 1). The original plantings included 591 individuals in 43 half-sib families, but some of these individuals were not alive when leaves were selected for DNA sampling in 2002.
As was reported previously, genetic variation was greater within each of the two sites than between the two sites (Lamboy et al., 1996). $\mathrm{F}_{\mathrm{st}}$ values among collection sites 6 and 9 were modest but significant $\left(\mathrm{F}_{\mathrm{st}}=0.07, \pm 0.05\right.$ by bootstrap process, $P<0.05$ by permutation), whereas the differentiation among half-sib families within a location was large $\left(\mathrm{F}_{\mathrm{st}}=0.19, \pm 0.04\right)$. Allelic richness (Petit et al., 1998) between the two regions was significantly different with each region having a set of private alleles. These findings support the creation of core collections for each sampling site.

For both site 6 and site 9, saturation analyses revealed that $>95 \%$ of the possible variation could be captured with 35 member core collections (Fig. 3 A and B). While these estimates were robust using genetic data, some trees from which genotypes were taken in 2002 died or did not flower in 2004 (Table 1). We compared redundancy curves with all tree samples taken in 2002 (core-1), with all healthy, live tree samples in 2004 (core-2), and with all flowering tree samples in 2004 (core-3) to determine how mortality and phenology impacted the assembly of these core collections.

The site 6 core- 1 collection included 35 accessions from the original 174 accessions. However, 14 of the original 174 accessions were not healthy and another 36 accessions were excluded from the original dataset because they were not flowering. Therefore, core-3 included 35 accessions selected from a population of 124 individuals. Similarly, the original dataset for site 9 had 278 accessions, but the core- 3 collection was selected from only 170 of those accessions that were healthy and flowering in 2004. Despite a $29 \%$ or $39 \%$ reduction in the original population size, a $6 \%$ and 7 $\%$ reduction in diversity was noted between the core- 1 and core- 3 collections from sites 6 and 9, respectively (Fig. 3 A and B). One entire half-sib family was lost from sub-site 9.00.

For both sites, the frequency of alleles in the entire genotyped population was very highly correlated with allele frequency in the core-1, core-2, and core- 3 collections (Fig. 4 A,B). Some alleles were lost as individuals were eliminated from the original populations. Site 6 had 64 alleles in the original population as determined in our SSR analyses. Core- 1 included 63 of these alleles, while core- 2 and core- 3 had 61 and 60 alleles, respectively, represented. For site 9 , the core- 1 , core- 2 , and core- 3 collections included 62, 57, and 57 alleles of the original 64 alleles. In all, 72 of the total 76 alleles in the combined populations were captured in the core- 3 collections from sites 6 and 9.

The core- 3 collection for site 6 included representatives of each of the 14 half-sib families. All of the subsampling sites were represented in the site 9 core- 3 collection. Eight of the 28 half-sib families for which DNA was available were not represented in the site 9 core- 3 collection (Tables 1-3).

We further validated the core collections by comparing allelic and phenotypic frequencies between the original and core- 3 collection populations. The core- 3 collections represented individuals with disease resistance. Within the original populations at site 6 that were screened for disease resistance, there were $64 \%$ and $42 \%$ incidences of fire blight and scab resistance, respectively. The site 6 core- 3 collection had $69 \%$ and $46 \%$ incidences of fire blight and scab resistance. In the original populations at site 9 screened for disease resistance, there were $51 \%$ and $37 \%$ incidence rates of fire blight and scab resistance, respectively. Sixty-three percent and $49 \%$ of the individuals in the core- 3 collection exhibited fire blight and scab resistance, respectively. Thus, the selected core-3 collections provide valuable alleles for disease resistance from the original populations. 
Table 1. Malus sieversii half-sib families from Kazakhstan collection sites 6 and 9.

\begin{tabular}{|c|c|c|c|c|c|c|c|c|c|c|}
\hline Identification & $\begin{array}{c}\text { Collection } \\
\text { year }\end{array}$ & Site & $\begin{array}{c}\text { Maternal } \\
\text { ID }\end{array}$ & $\begin{array}{c}\text { Trees } \\
\text { sampled } \\
\#\end{array}$ & $\begin{array}{c}\text { Fruit } \\
\text { sampled } \\
\#\end{array}$ & $\begin{array}{c}\text { Seeds } \\
\text { collected } \\
\# \\
\end{array}$ & $\begin{array}{c}\text { Seedlings } \\
\text { in field } \\
\#\end{array}$ & $\begin{array}{c}\text { Sampled } \\
\text { for DNA } \\
\#\end{array}$ & $\begin{array}{c}\text { Alive } \\
\text { in } 2004 \\
\#\end{array}$ & $\begin{array}{c}\text { Flowering } \\
\text { in } 2004 \\
\#\end{array}$ \\
\hline GMAL 3975 & 1995 & 6.00 & & 1 & 8 & 60 & 14 & 11 & 11 & 8 \\
\hline GMAL 3989 & 1995 & 6.00 & & 1 & 8 & -- & 14 & 14 & 14 & 14 \\
\hline GMAL 3999 & 1995 & 6.00 & & 1 & 8 & 72 & 15 & 12 & 11 & 8 \\
\hline GMAL 4000 & 1995 & 6.00 & & 1 & 8 & 43 & 14 & 11 & 7 & 5 \\
\hline GMAL 4002 & 1995 & 6.00 & & 1 & 8 & 61 & 16 & 16 & 16 & 16 \\
\hline GMAL 3682 & 1995 & 6.01 & & 1 & 150 & 933 & 12 & 11 & 11 & 6 \\
\hline GMAL 3683 & 1995 & 6.01 & & 1 & 150 & 820 & 13 & 13 & 10 & 9 \\
\hline GMAL 3684 & 1995 & 6.01 & & 1 & 70 & 325 & 15 & 13 & 10 & 8 \\
\hline GMAL 3685 & 1995 & 6.01 & & 1 & 40 & 148 & 15 & 9 & 9 & 7 \\
\hline GMAL 3687 & 1995 & 6.01 & & 1 & 150 & 645 & 14 & 9 & 9 & 4 \\
\hline GMAL 3688 & 1995 & 6.01 & & 1 & 200 & 1225 & 15 & 13 & 12 & 6 \\
\hline GMAL 3689 & 1995 & 6.01 & & 1 & 60 & 270 & 17 & 15 & 14 & 12 \\
\hline GMAL 3690 & 1995 & 6.01 & & 1 & 150 & 760 & 15 & 14 & 14 & 11 \\
\hline GMAL 3691 & 1995 & 6.01 & & 1 & 150 & 694 & 15 & 13 & 12 & 10 \\
\hline Total & & & & & 1160 & 6056 & 204 & 174 & 160 & 124 \\
\hline GMAL 3607 & 1995 & 9.00 & PI 613970 & 1 & 30 & 1020 & 15 & 5 & 3 & 0 \\
\hline GMAL 3762 & 1995 & 9.00 & & 1 & 5 & 48 & 15 & 12 & 10 & 7 \\
\hline GMAL 3764 & 1995 & 9.00 & & 1 & 5 & 45 & 14 & 14 & 12 & 7 \\
\hline GMAL 3775 & 1995 & 9.00 & & 1 & 5 & 36 & 13 & 8 & 8 & 5 \\
\hline GMAL 3781 & 1995 & 9.00 & & 1 & 5 & 33 & 13 & 12 & 10 & 9 \\
\hline GMAL 3784 & 1995 & 9.00 & & 1 & 5 & 35 & 15 & 6 & 2 & 2 \\
\hline GMAL 3785 & 1995 & 9.00 & & 1 & 5 & 32 & 12 & 3 & 3 & 3 \\
\hline GMAL 3616 & 1995 & 9.01 & PI 613973 & 1 & 30 & 227 & 15 & 12 & 9 & 8 \\
\hline GMAL 3619 & 1995 & 9.01 & PI 613974 & 1 & 30 & 250 & 13 & 8 & 6 & 6 \\
\hline GMAL 3626 & 1995 & 9.02 & & 1 & 30 & 275 & 13 & 7 & 6 & 5 \\
\hline GMAL 3627 & 1995 & 9.02 & & 1 & 60 & 326 & 13 & 13 & 12 & 12 \\
\hline GMAL 3629 & 1995 & 9.02 & & 1 & 30 & 287 & 15 & 13 & 13 & 11 \\
\hline GMAL 3631 & 1995 & 9.02 & & 1 & 30 & 229 & 13 & 3 & 2 & 1 \\
\hline GMAL 3608 & 1995 & 9.03 & PI 613971 & 1 & 150 & 646 & 14 & 11 & 10 & 8 \\
\hline GMAL 3610 & 1995 & 9.03 & & 1 & 30 & 124 & 12 & 10 & 9 & 9 \\
\hline GMAL 3614 & 1995 & 9.03 & PI 613972 & 1 & 30 & 228 & 12 & 10 & 7 & 6 \\
\hline GMAL 3620 & 1995 & 9.04 & & 1 & 15 & 55 & 13 & 11 & 10 & 9 \\
\hline GMAL 3622 & 1995 & 9.04 & & 1 & 40 & 255 & 13 & 12 & 8 & 8 \\
\hline GMAL 3623 & 1995 & 9.04 & PI 613975 & 1 & 30 & 218 & 13 & 6 & 6 & 5 \\
\hline GMAL 3625 & 1995 & 9.04 & PI 613976 & 1 & 15 & 232 & 14 & 8 & 5 & 5 \\
\hline GMAL 3635 & 1995 & 9.05 & & 1 & 30 & 256 & 13 & 4 & 3 & 3 \\
\hline GMAL 3636 & 1995 & 9.05 & PI 613978 & 1 & 35 & 324 & 14 & 10 & 7 & 2 \\
\hline GMAL 3637 & 1995 & 9.05 & PI 613979 & 1 & 50 & 323 & 15 & 11 & 5 & 4 \\
\hline GMAL 3638 & 1995 & 9.05 & & 1 & 30 & 255 & 12 & 10 & 8 & 3 \\
\hline GMAL 3643 & 1995 & 9.05 & PI 613977 & 1 & 150 & 1035 & 14 & 9 & 7 & 3 \\
\hline GMAL 4020 & 1996 & 9.05 & PI 613954 & 1 & 4 & 32 & 12 & 10 & 10 & 5 \\
\hline GMAL 4024 & 1996 & 9.05 & PI 613987 & 1 & 100 & 512 & 25 & 17 & 12 & 8 \\
\hline GMAL 4103 & 1996 & 9.05 & & 60 & 8 & 72 & 5 & 4 & 2 & 1 \\
\hline GMAL 4155 & 1996 & 9.05 & & 60 & 8 & 41 & 7 & 7 & 5 & 3 \\
\hline PI 613970 & 1996 & 9.00 & & 1 & & & 1 & 1 & 1 & 1 \\
\hline PI 613973 & 1996 & 9.01 & & 1 & & & 1 & 1 & 1 & 1 \\
\hline PI 613974 & 1996 & 9.01 & & 1 & & & 1 & 1 & 1 & 1 \\
\hline PI 613971 & 1996 & 9.03 & & 1 & & & 1 & 1 & 1 & 1 \\
\hline PI 613972 & 1996 & 9.03 & & 1 & & & 1 & 1 & 1 & 1 \\
\hline PI 613975 & 1996 & 9.04 & & 1 & & & 1 & 1 & 1 & 1 \\
\hline PI 613976 & 1996 & 9.04 & & 1 & & & 1 & 1 & 1 & 1 \\
\hline PI 613978 & 1996 & 9.05 & & 1 & & & 1 & 1 & 1 & 1 \\
\hline PI 613979 & 1996 & 9.05 & & 1 & & & 1 & 1 & 1 & 1 \\
\hline PI 613977 & 1996 & 9.05 & & 1 & & & 1 & 1 & 1 & 1 \\
\hline PI 613954 & 1996 & 9.05 & & 1 & & & 1 & 1 & 1 & 1 \\
\hline PI 613987 & 1996 & 9.05 & & 1 & & & 1 & 1 & 1 & 1 \\
\hline Total & & & & & 995 & 7451 & 399 & 278 & 222 & 170 \\
\hline
\end{tabular}

\section{Discussion}

Many research programs are utilizing wild Malus germplasm from Kazakhstan to increase disease resistance and stress tolerance for new apple cultivars (Forsline et al., 2003). However, few studies have looked at the molecular diversity of the wild materials. Lamboy et al. (1996) used 259 M. sieversii seedlings belonging to 31 half-sib families to determine allozyme diversity across four regions in Kazakhstan. Those plant materials were collected in
1989 and 1993 . In those analyses, $85 \%$ of the enzyme variability was due to differences among half-sib families within locations, and only $15 \%$ was due to differences among regions. They concluded that thoroughly collecting from a few large populations effectively captured the diversity of this species.

Based on our SSR results, we also conclude that many alleles are shared between the $M$. sieversii seedlings from sites 6 and 9; however, allele frequencies do vary, as shown using $\mathrm{F}_{\mathrm{st}}$ calculations and by comparing allelic richness estimates. The inherent 


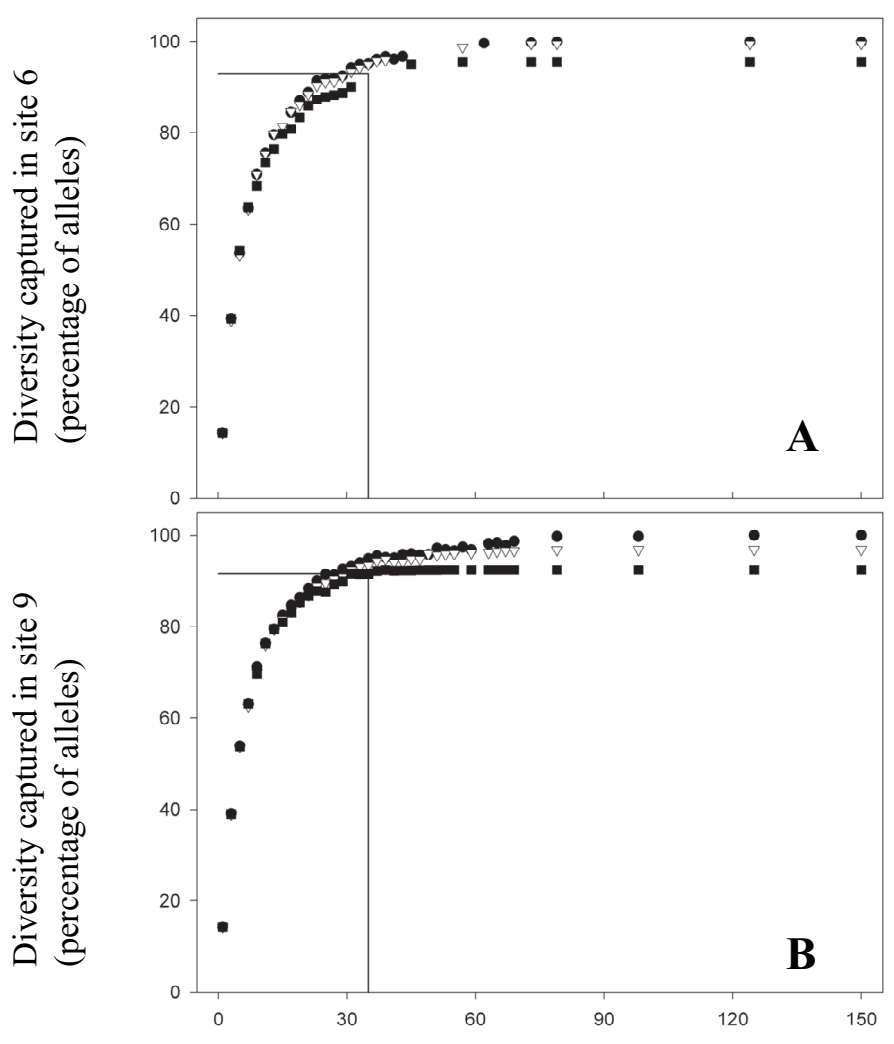

Number of individuals in core

Fig. 3. Redundancy plots are shown for site 6 (A) and site 9 (B). Each plot shows the accumulation of allelic and phenotypic diversity with increasing core size. Diversity is represented as a percentage out of the total number of allelic and phenotypic states in the collection. Each point represents the mean of 20 runs using the maximization algorithm in MSTRAT software. The convex shape of the curve suggests that above a critical point adding more individuals to a core does not greatly increase diversity in the core collection. The intersection of the vertical and horizontal lines marks the size and diversity of the core collections proposed in this study. In each plot, the redundancy analyses are shown for the living seedlings in 2002 (circles), healthy seedlings in 2004 (triangles) and trees flowering in 2004 (squares) that were used to generate the core-1, core-2 and core- 3 collections, respectively. In site 6 (A) the core- 3 contains 35 individuals and captures $95.5 \%$ of the diversity and in site 9 (B) the core- 3 contains 35 individuals and captures $92.5 \%$ of the diversity.

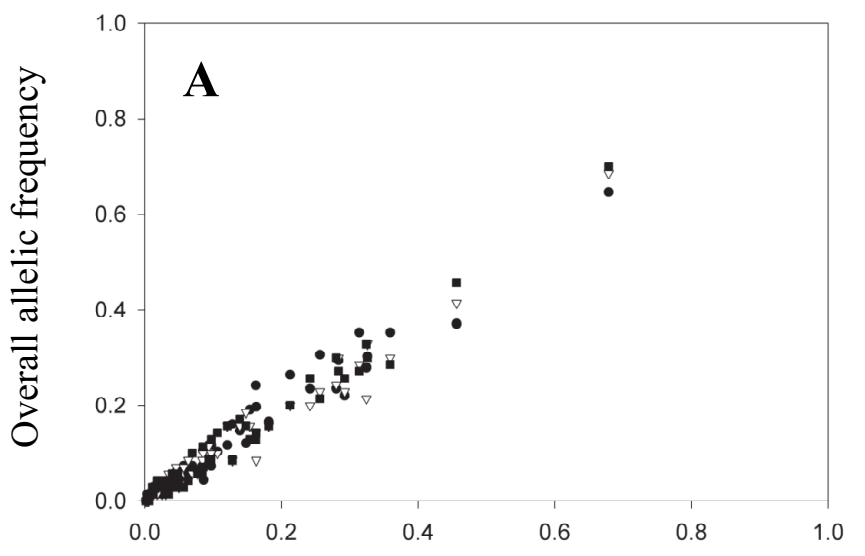

Allelic frequencies in core redundancy of alleles in the two populations allowed us to capture $90 \%$ of the alleles in the original population in the core- 3 collections, despite the loss of $29 \%$ to $39 \%$ of the individuals from mortality, poor health, or "unwilling" phenology.

Core collections have been established for many plant collections to assist in collection maintenance and distribution. Often core collections are established based on sample geographical data and morphological descriptors (Clark et al., 1997; Holbrook et al., 1993; Skinner et al., 1999; Tohme et al., 1995). Neutral markers such as those available from isozymes, amplified fragment length polymorphisms, or SSR analyses also provide valuable data on allelic diversity and richness for the development of core collections (Clark et al., 1997). When core collections are designed based on genotypic characters, genetic representation is most complete (McKhann et al., 2004).

Most models use plant collections with thousands of accessions to base estimates for optimal core collection size. These models suggest that selection of $10 \%$ of the original accessions should retain roughly $70 \%$ of the alleles in the total collection (Schoen and Brown, 1995). Generally, this strategy preserves alleles that are not widespread, but may provide important sources of diversity (Bataillon et al., 1996; Schoen and Brown, 1995). A main objective of the study presented here was to identify individuals that effectively capture allelic and phenotypic diversity within two sites in Kazakhstan. The core collections we developed serve as sources for alleles, rather than sources of genotypes or clones. The maximization strategy used includes individuals in the core collection with high allelic richness and low redundancy. We determined that 35 accessions effectively capture greater than $95 \%$ of the alleles within the $M$. sieversii populations in sites 6 and 9 . The designated core collections include more than $10 \%$ of the total accessions. For site 6 , these 35 accessions represent $20 \%$ and $28 \%$ of the original and flowering populations, respectively. For site 9, these 35 accessions represent $13 \%$ and $21 \%$ of the original and flowering populations, respectively. Since the accessions from site 6 , overall, have a greater allelic diversity per allele than the accessions from site 9, the core includes a larger percentage of individuals. The core size of 35 individuals per site falls within the range of 25 to 100 accessions per ecogeographical area suggested by Crossa et al. (1993).

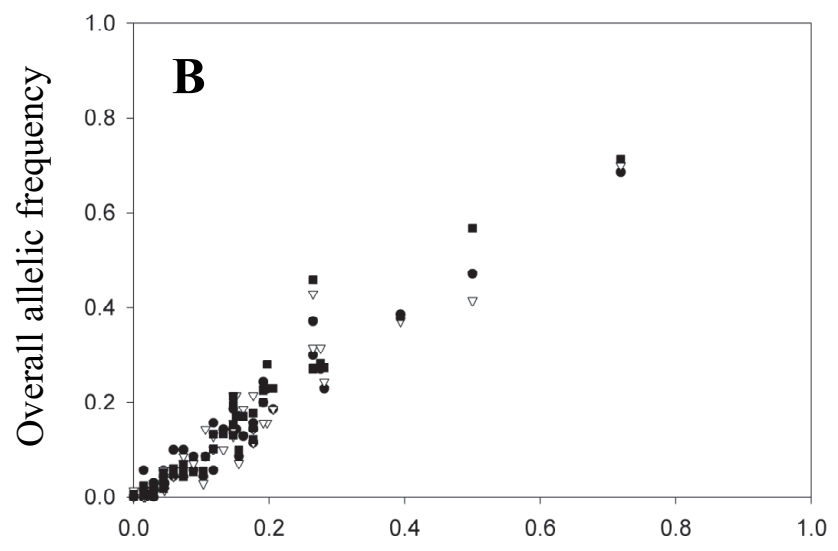

Allelic frequencies in core

Fig. 4. Bi-plots show allelic frequencies in the core collection versus the complete collection of $M$. sieversii collected from Kazakhstan sites 6 (A) and 9 (B). These scatter plots show a strong positive correlation between allelic frequencies in core-1, core-2, and core-3 collections and their respective source collection (circles represent alleles from living seedlings in 2002, triangles represent alleles from healthy seedlings in 2004 and squares represent alleles from trees flowering in 2004). These data suggest that the core collections are genetically representative. 
Table 2. M. sieversii phenotypic characterization data is provided for site 6 in Kazahstan.

\begin{tabular}{|c|c|c|c|c|c|c|c|c|c|c|c|c|c|c|c|}
\hline $\begin{array}{c}\text { Identification } \\
\text { number }\end{array}$ & Subsite & $\begin{array}{c}\text { Year } \\
\text { collected }\end{array}$ & $\begin{array}{c}\text { Characterization } \\
\text { date }\end{array}$ & $\begin{array}{l}\text { Fire blight } \\
\text { resistance }\end{array}$ & $\begin{array}{c}\text { Scab } \\
\text { resistance }\end{array}$ & $\begin{array}{l}\text { Flesh } \\
\text { color }\end{array}$ & $\begin{array}{l}\text { Flesh } \\
\text { firmness }\end{array}$ & $\begin{array}{l}\text { Flesh } \\
\text { flavor }\end{array}$ & $\begin{array}{c}\text { Flesh } \\
\text { oxidation }\end{array}$ & $\begin{array}{c}\begin{array}{c}\text { Fruit } \\
\text { ground } \\
\text { color }\end{array} \\
\end{array}$ & $\begin{array}{c}\text { Fruit } \\
\text { juiciness }\end{array}$ & $\begin{array}{l}\text { Weight } \\
\text { (g) }\end{array}$ & $\begin{array}{c}\text { Fruit } \\
\text { overcolor }\end{array}$ & $\begin{array}{c}\text { Overcolor } \\
\text { on fruit } \\
\% \\
\end{array}$ & $\begin{array}{c}\text { Fruit } \\
\text { overcolor } \\
\text { pattern }\end{array}$ \\
\hline GMAL 3682.e & 6.01 & 1995 & - & Resistant & Susceptible & - & - & - & - & - & - & - & - & - & - \\
\hline GMAL 3682.f & 6.01 & 1995 & - & Resistant & Susceptible & - & - & - & - & - & - & - & - & - & - \\
\hline GMAL 3682.k & 6.01 & 1995 & - & Resistant & Susceptible & - & - & - & - & - & - & - & - & - & - \\
\hline GMAL 3683.d & 6.01 & 1995 & 2001 & Susceptible & Susceptible & Cream, green & Semifirm & Subacid & $>10 \%$ & Lt green & Dry & 25 & Red & 60 & Striped \\
\hline GMAL 3683.I & 6.01 & 1995 & 2002 & Resistant & Resistant & Cream, green & Firm & Astringent & $>10 \%$ & Lt green & Dry & 32 & None & 0 & None \\
\hline GMAL 3683.n & 6.01 & 1995 & 2001 & Susceptible & Susceptible & Cream, green & Firm & Acid & $>10 \%$ & Green & Dry & 32 & Brown & 10 & Striped \\
\hline GMAL 3684.a & 6.01 & 1995 & 2003 & Resistant & Resistant & Cream & Semifirm & Astringent & $>10 \%$ & Green & Dry & 35 & Red & 30 & Striped \\
\hline GMAL 3684.b & 6.01 & 1995 & 2001 & Susceptible & Susceptible & Cream, green & Semifirm & Subacid & $>10 \%$ & Green & Dry & 52 & None & - & None \\
\hline GMAL 3684.1 & 6.01 & 1995 & 2001 & Susceptible & Resistant & Cream, green & Semifirm & Astringent & $>10 \%$ & Green & Dry & 35 & Red & 50 & Blush \\
\hline GMAL 3685.d & 6.01 & 1995 & 2002 & Susceptible & Resistant & Cream, green & Semifirm & Astringent & $>10 \%$ & Green & Dry & 34 & Red & 20 & Striped \\
\hline GMAL 3685.e & 6.01 & 1995 & 2003 & Resistant & Susceptible & Cream, green & Firm & Astringent & $>10 \%$ & Green & Dry & 23 & Brown & 10 & Striped \\
\hline GMAL 3685.f & 6.01 & 1995 & 2002 & Resistant & Susceptible & Cream, green & Semifirm & Astringent & $>10 \%$ & Lt green & Dry & 24 & Pink & 5 & Blush \\
\hline GMAL 3687.d & 6.01 & 1995 & - & Resistant & Susceptible & - & - & - & - & - & - & - & - & - & - \\
\hline GMAL 3687.h & 6.01 & 1995 & 2001 & Susceptible & Susceptible & White & Soft & Sweet & $5-10 \%$ & Green & Dry & 47 & None & 0 & None \\
\hline GMAL 3688.n & 6.01 & 1995 & 2003 & Resistant & Resistant & Cream, green & Firm & Subacid & $>10 \%$ & Lt green & Medium & 33 & None & - & None \\
\hline GMAL 3689.c & 6.01 & 1995 & 2001 & Resistant & Resistant & Cream, green & Semifirm & Astringent & $>10 \%$ & Lt green & Moderate & 30 & Red & 1 & Blush \\
\hline GMAL 3689.n & 6.01 & 1995 & 2003 & Resistant & Resistant & Cream, green & Semifirm & Acid & $>10 \%$ & Green & Medium & 44 & Pink & 5 & Striped \\
\hline GMAL 3689.p & 6.01 & 1995 & 2002 & Resistant & Susceptible & Cream, green & Semifirm & Astringent & $>10 \%$ & Lt green & Dry & 28 & - & - & - \\
\hline GMAL $3690 . \mathrm{d}$ & 6.01 & 1995 & 2001 & Susceptible & Susceptible & Cream, green & Semifirm & Subacid & $5-10 \%$ & Green & Dry & 44 & Pink & 20 & Striped \\
\hline GMAL 3690.0 & 6.01 & 1995 & 2001 & Resistant & Susceptible & Cream, green & Soft & Acid & $1-4 \%$ & Lt green & Very dry & 23 & Brown & 60 & Striped \\
\hline GMAL 3691.j & 6.01 & 1995 & - & Resistant & Susceptible & - & - & - & - & - & - & - & - & - & - \\
\hline GMAL $3691 . \mathrm{m}$ & 6.01 & 1995 & 2001 & Susceptible & Susceptible & Cream, green & Semifirm & Subacid & $>10 \%$ & Lt green & Very dry & 38 & Red & 60 & Blush \\
\hline GMAL 3975.d & 6.01 & 1995 & 2001 & Resistant & Resistant & Cream, green & Firm & Subacid & $>10 \%$ & Green & Medium & 39 & Red & 10 & Striped \\
\hline GMAL 3975.g & 6.01 & 1995 & 2001 & Susceptible & Susceptible & Cream & Soft & Subacid & $>10 \%$ & Green & Medium & 26 & None & 0 & None \\
\hline GMAL 3975.k & 6.01 & 1995 & 2001 & Resistant & Resistant & Cream, green & Soft & Aromatic & $0-1 \%$ & Yellow & Dry & 39 & None & 0 & None \\
\hline GMAL 3975.1 & 6.01 & 1995 & 2000 & Resistant & Resistant & Green & Hard & Subacid & $5-10 \%$ & Green & Very juicy & 47 & Yellow & 20 & Blush \\
\hline GMAL 3975.m & 6.01 & 1995 & 2002 & Resistant & Resistant & Cream, green & Semifirm & Subacid & $>10 \%$ & Lt green & Dry & 18 & - & - & - \\
\hline GMAL 3989.f & 6.01 & 1995 & 2002 & Resistant & Susceptible & Cream & Soft & Subacid & $>10 \%$ & Lt green & Very dry & 44 & Pink & 5 & Striped \\
\hline GMAL 3989.k & 6.01 & 1995 & 2002 & Resistant & Resistant & Cream, green & Soft & Subacid & $>10 \%$ & Green & Medium & 34 & None & 0 & None \\
\hline GMAL 3999.b & 6.01 & 1995 & 2003 & Resistant & Susceptible & White & Firm & Astringent & $>10 \%$ & Green & Dry & 19 & Pink & 1 & Striped \\
\hline GMAL $4000 . b$ & 6.01 & 1995 & 2003 & Resistant & Resistant & Cream, green & Semifirm & Subacid & $>10 \%$ & Green & Medium & 16 & Red & 20 & Striped \\
\hline GMAL $4000 . \mathrm{g}$ & 6.01 & 1995 & 2003 & Susceptible & Susceptible & Cream, green & - & - & $1-4 \%$ & Lt green & Dry & 27 & Pink & 40 & Striped \\
\hline GMAL4002.d & 6.01 & 1995 & 2002 & Resistant & Resistant & Cream & Semifirm & Astringent & $>10 \%$ & Lt green & Dry & 21 & Yellow & 40 & Blush \\
\hline GMAL 4002.e & 6.01 & 1995 & 2001 & Resistant & Resistant & Cream, green & Semifirm & Astringent & $5-10 \%$ & Lt green & Medium & 29 & None & 0 & None \\
\hline GMAL 4002.h & 6.01 & 1995 & 2002 & Susceptible & Resistant & Cream, green & Soft & Subacid & $>10 \%$ & Lt green & Very dry & 34 & - & - & Striped \\
\hline
\end{tabular}

Table 3. M. sieversii phenotypic characterization data is provided for site 9 in Kazakhstan.

\begin{tabular}{|c|c|c|c|c|c|c|c|c|c|c|c|c|c|c|c|}
\hline $\begin{array}{c}\text { Identification } \\
\text { number }\end{array}$ & Subsite & $\begin{array}{c}\text { Year } \\
\text { collected }\end{array}$ & $\begin{array}{c}\text { Characterization } \\
\text { date }\end{array}$ & $\begin{array}{l}\text { Fire blight } \\
\text { resistance }\end{array}$ & $\begin{array}{l}\text { Scab } \\
\text { resistance }\end{array}$ & $\begin{array}{l}\text { Flesh } \\
\text { color }\end{array}$ & $\begin{array}{c}\text { Flesh } \\
\text { firmness }\end{array}$ & $\begin{array}{l}\text { Flesh } \\
\text { flavor }\end{array}$ & $\begin{array}{c}\text { Flesh } \\
\text { oxidation }\end{array}$ & $\begin{array}{c}\begin{array}{c}\text { Fruit } \\
\text { ground }\end{array} \\
\text { color } \\
\end{array}$ & $\begin{array}{c}\text { Fruit } \\
\text { juiciness }\end{array}$ & Weight & $\begin{array}{c}\text { Fruit } \\
\text { overcolor }\end{array}$ & $\begin{array}{c}\text { Overcolor } \\
\text { on fruit } \\
\% \\
\end{array}$ & $\begin{array}{c}\text { Fruit } \\
\text { overcolor } \\
\text { pattern } \\
\end{array}$ \\
\hline GMAL 3764.e & 9.00 & 1995 & 2002 & Susceptible & Susceptible & Cream, yellow & Semifirm & Subacid & $>10 \%$ & Lt green & Medium & 47 & Pink & 5 & Blush \\
\hline GMAL 3764.1 & 9.00 & 1995 & 2002 & Resistant & Susceptible & Cream, green & Semifirm & Subacid & $>10 \%$ & Lt green & Very dry & 29 & Red & 40 & Striped \\
\hline GMAL $3762 . \mathrm{g}$ & 9.00 & 1995 & 2000 & Resistant & Resistant & White & Soft & Subacid & $0-1 \%$ & Green & Very dry & 50 & Yellow & 60 & Blush \\
\hline GMAL 3762.n & 9.00 & 1995 & 2003 & Susceptible & Resistant & White, cream & - & - & $1-4 \%$ & Lt green & Dry & 29 & None & 0 & None \\
\hline GMAL 3781.b & 9.00 & 1995 & 2003 & Resistant & Susceptible & White & Soft & Subacid & $>10 \%$ & Lt green & Dry & 22 & Yellow & 90 & Blush \\
\hline GMAL 3781.c & 9.00 & 1995 & 2003 & Resistant & Susceptible & Pink & Firm & Astringent & $>10 \%$ & Green & Dry & 14 & Red & 90 & Blush \\
\hline GMAL 3781.h & 9.00 & 1995 & 2002 & Susceptible & Resistant & Cream & Soft & Subacid & $>10 \%$ & Lt green & Moderate & 11 & None & - & - \\
\hline GMAL 3781.n & 9.00 & 1995 & - & Resistant & Resistant & - & 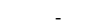 & - & - & - & - & - & & - & - \\
\hline GMAL 3784.d & 9.00 & 1995 & 2000 & Susceptible & Resistant & Cream, green & Soft & Aromatic & $>10 \%$ & Green & Medium & 76 & Yellow & 20 & Blush \\
\hline GMAL 3785.b & 9.00 & 1995 & 2003 & Resistant & Susceptible & Cream & Semifirm & Astringent & $>10 \%$ & Green & Medium & 13 & None & - & - \\
\hline GMAL $3785 . \mathrm{k}$ & 9.00 & 1995 & 2003 & Susceptible & Resistant & Cream, yellow & Semifirm & Astringent & $>10 \%$ & Lt green & Very dry & 25 & Yellow & 95 & Blush \\
\hline GMAL 3616.d & 9.01 & 1995 & 2001 & Resistant & Susceptible & White, green & Soft & Subacid & $>10 \%$ & Green & Dry & 42 & None & - & - \\
\hline GMAL 3619.j & 9.01 & 1995 & 2001 & Resistant & Susceptible & Cream & Soft & Sweet & $5-10 \%$ & Lt green & Medium & 56 & Orange & 10 & Blush \\
\hline GMAL 3619.m & 9.01 & 1995 & 2001 & Resistant & Susceptible & Cream, green & Semifirm & Subacid & $>10 \%$ & Lt green & Medium & 50 & Yellow & 5 & Striped \\
\hline GMAL 4103.a & 9.01 & 1996 & 2003 & Resistant & Resistant & White & Soft & Subacid & $1-4 \%$ & Lt yellow & Very dry & 24 & None & - & - \\
\hline GMAL 3627.a & 9.02 & 1995 & 2003 & Resistant & Susceptible & Cream & Semifirm & Subacid & $>10 \%$ & Lt green & Dry & 34 & None & - & - \\
\hline GMAL 3627.1 & 9.02 & 1995 & 2002 & Resistant & Resistant & Cream & Semifirm & Astringent & $>10 \%$ & Lt yellow & Medium & 27 & Red & 25 & Striped \\
\hline GMAL 3629.n & 9.02 & 1995 & 2002 & Susceptible & Resistant & Cream, green & Soft & Acid & $>10 \%$ & Lt green & Dry & 40 & None & - & - \\
\hline GMAL 4024.n & 9.02 & 1996 & 2003 & Susceptible & Resistant & Cream & Semifirm & Sweet & $5-10 \%$ & Green & Dry & 37 & Red & 75 & Striped \\
\hline GMAL 3608.b & 9.03 & 1995 & 2002 & Resistant & Susceptible & Cream & Soft & Aromatic & $>10 \%$ & Lt green & Dry & 38 & Red & 10 & Striped \\
\hline GMAL 3610.b & 9.03 & 1995 & 2001 & Resistant & Resistant & Cream, green & Semifirm & Astringent & $>10 \%$ & Lt green & Medium & 23 & Pink & 25 & Blush \\
\hline GMAL 3610.1 & 9.03 & 1995 & 2002 & Resistant & Resistant & Cream, green & Semifirm & Astringent & $>10 \%$ & Lt green & Medium & 21 & & - & \\
\hline GMAL 3614.a & 9.03 & 1995 & 2001 & Susceptible & Resistant & Cream, green & Semifirm & Astringent & $>10 \%$ & Lt green & Medium & 33 & Pink & 30 & Blush \\
\hline GMAL 3614.g & 9.03 & 1995 & 2001 & Resistant & Resistant & Cream, green & Semifirm & Acid & $>10 \%$ & Green & Dry & 62 & Brown & 40 & Blush \\
\hline PI 613972.2 & 9.03 & 1995 & 2003 & Susceptible & Susceptible & White & Semifirm & Subacid & $1-4 \%$ & Yellow & Very dry & 114 & Pink & 5 & Blush \\
\hline GMAL 3620.e & 9.04 & 1995 & - & Resistant & Susceptible & - & - & - & - & - & - & - & - & - & - \\
\hline GMAL 3620.m & 9.04 & 1995 & 2001 & Resistant & Resistant & Cream, green & Semifirm & Astringent & $>10 \%$ & Lt yellow & Dry & 50 & Red & 5 & Blush \\
\hline GMAL 3622.m & 9.04 & 1995 & 2001 & Resistant & Susceptible & Cream, green & Semifirm & Astringent & $>10 \%$ & Lt yellow & Very dry & 28 & Pink & 10 & Splashed \\
\hline GMAL 3623.e & 9.04 & 1995 & 2003 & Susceptible & Susceptible & Cream & Hard & Acid & $>10 \%$ & Green & Moderate & 47 & Red & 65 & Striped \\
\hline GMAL 3623.f & 9.04 & 1995 & 2002 & Resistant & Susceptible & Cream, green & Semifirm & Subacid & $>10 \%$ & Lt green & Dry & 63 & - & - & - \\
\hline GMAL 3625.a & 9.04 & 1995 & 2002 & Susceptible & Resistant & Cream, green & Semifirm & Astringent & $>10 \%$ & Lt green & Medium & 43 & - & - & - \\
\hline PI 613975.1 & 9.04 & 1995 & 2003 & Susceptible & Susceptible & Cream, green & Semifirm & Aromatic & $>10 \%$ & Lt green & Medium & 158 & Pink & 65 & Striped \\
\hline GMAL 3636.h & 9.05 & 1995 & - & Resistant & Resistant & - & - & - & - & - & - & - & - & - & - \\
\hline GMAL 3638.b & 9.05 & 1995 & 2003 & Susceptible & Not tested & Cream, green & Semifirm & Subacid & $5-10 \%$ & Lt green & Dry & 65 & Pink & 10 & Striped \\
\hline GMAL 4020.I & 9.05 & 1996 & 2002 & Resistant & Susceptible & Cream, yellow & Semifirm & Subacid & $>10 \%$ & Lt yellow & Medium & 11 & Red & 80 & Striped \\
\hline
\end{tabular}




\begin{tabular}{|c|c|c|c|c|c|c|c|c|}
\hline $\begin{array}{c}\text { Fruit surface } \\
\text { with russet } \\
\% \\
\end{array}$ & $\begin{array}{c}\text { Fruit } \\
\text { russet } \\
\text { location }\end{array}$ & $\begin{array}{c}\text { Fruit } \\
\text { russet } \\
\text { type }\end{array}$ & Fruit shape & $\begin{array}{c}\text { Fruit } \\
\text { shape } \\
\text { uniformity }\end{array}$ & $\begin{array}{c}\text { Fruit } \\
\text { size } \\
\text { uniformity }\end{array}$ & $\begin{array}{l}\text { Fruit } \\
\text { texture }\end{array}$ & $\begin{array}{c}\text { Harvest } \\
\text { season }\end{array}$ & $\begin{array}{c}\text { Soluble } \\
\text { solids } \\
\% \\
\end{array}$ \\
\hline
\end{tabular}

\begin{tabular}{|c|c|c|c|c|c|c|c|c|}
\hline & $\begin{array}{ll}- \\
-\end{array}$ & - & - & - & - & - & - & - \\
\hline & - & - & - & - & - & - & - & - \\
\hline 1 & Pedicel & Extr. fine & Globose-conical & Variable & Variable & Coarse & Medium/late & 13.8 \\
\hline 0 & None & None & Globose & Uniform & Uniform & Medium & - & 11.8 \\
\hline 5 & Pedicel & Extr. fine & Globose & Variable & Variable & Coarse & Medium/late & 12.6 \\
\hline 2 & Pedicel, calyx & Extr. fine & Flat-globose & Variable & Variable & Coarse & Medium & 10.6 \\
\hline 1 & Pedicel & Extr. fine & Globose-conical & Uniform & Uniform & Medium & Early & 11.0 \\
\hline 10 & Pedicel & Med. heavy & Globose-conical & Variable & Variable & Coarse & Medium/early & 14.3 \\
\hline 5 & Entire fruit & Extr. fine & Flat-globose & Uniform & Uniform & Medium & - & 12.4 \\
\hline 10 & Pedicel & Extr. fine & Globose & Uniform & Variable & Medium & Late & 14.1 \\
\hline 4 & Entire fruit & Extr. fine & Globose & Uniform & Variable & Coarse & - & 12.5 \\
\hline- & - & - & - & - & - & - & - & - \\
\hline 5 & Pedicel & Extr. fine & Flat-globose & Variable & Uniform & Medium & Medium/late & 13.5 \\
\hline 3 & Pedicel & Extr. fine & Flat-globose & Variable & Uniform & Medium & Early & 9.9 \\
\hline 1 & Pedicel & Extr. fine & Globose & Uniform & Uniform & Coarse & Medium & 13.7 \\
\hline 2 & Pedicel, calyx & Extr. fine & Flat-globose & Variable & Uniform & Medium & Late & 11.2 \\
\hline 1 & Pedicel, calyx & Med. heavy & Globose-conical & Variable & Uniform & Medium & - & 11.5 \\
\hline 1 & Pedicel & Extr. fine & Globose-conical & Uniform & - & Coarse & Extremely early & 12.0 \\
\hline 5 & Pedicel & Extr. fine & Globose & Variable & Variable & Coarse & Early & 12.0 \\
\hline- & - & - & - & - & - & - & - & - \\
\hline 1 & Pedicel & Extr. fine & Globose & Uniform & Uniform & Medium & Medium & 10.7 \\
\hline 5 & Pedicel & Extr. fine & Globose & Uniform & Uniform & Coarse & Medium/late & 13.5 \\
\hline 5 & Pedicel & Extr. fine & Globose & Uniform & Uniform & Fine & Medium/late & 11.5 \\
\hline 1 & Pedicel & Extr. fine & Globose-conical & Variable & Variable & Medium & Medium & 12.1 \\
\hline- & - & - & Globose-conical & Uniform & Uniform & Fine & Early & 11.5 \\
\hline 5 & Entire fruit & Extr. fine & Flat-globose & Uniform & Variable & Medium & - & 11.6 \\
\hline 1 & Pedicel & Extr. fine & Flat-globose & Variable & Uniform & Fine & - & 10.7 \\
\hline 10 & Entire fruit & Med. heavy & Globose & Variable & Variable & Medium & - & 12.8 \\
\hline 1 & Pedicel & Extr. fine & Conical & Variable & Variable & Coarse & Medium/early & 12.9 \\
\hline 1 & Calyx & Extr. fine & Globose-conical & Variable & Variable & Coarse & Early & 11.0 \\
\hline 1 & Pedicel & Extr. fine & Globose & Uniform & Uniform & - & Very early & 9.7 \\
\hline 2 & Calyx & Extr. fine & Flat-globose & Uniform & Variable & Medium & - & 11.1 \\
\hline 5 & Pedicel & Extr. fine & Globose-conical & Variable & Variable & Medium & Medium & 11.8 \\
\hline 2 & Pedicel, calyx & Med. heavy & Globose & Variable & Variable & Coarse & - & 12.2 \\
\hline
\end{tabular}

\begin{tabular}{|c|c|c|c|c|c|c|c|c|}
\hline $\begin{array}{c}\text { Fruit surface } \\
\text { with russet } \\
\%\end{array}$ & $\begin{array}{c}\text { Fruit } \\
\text { russet } \\
\text { location }\end{array}$ & $\begin{array}{l}\text { Fruit } \\
\text { russet } \\
\text { type }\end{array}$ & Fruit shape & $\begin{array}{c}\text { Fruit } \\
\text { shape } \\
\text { uniformity }\end{array}$ & $\begin{array}{c}\text { Fruit } \\
\text { size } \\
\text { uniformity }\end{array}$ & $\begin{array}{l}\text { Fruit } \\
\text { texture }\end{array}$ & $\begin{array}{c}\text { Harvest } \\
\text { season }\end{array}$ & $\begin{array}{c}\text { Soluble } \\
\text { solids } \\
\%\end{array}$ \\
\hline 1 & Pedicel & Extr. Fine & Globose & Variable & Variable & Medium & - & 10.1 \\
\hline - & - & - & Flat-globose & Uniform & Uniform & Medium & - & 11.0 \\
\hline - & - & - & Globose & Uniform & Uniform & Fine & Very early & 10.7 \\
\hline 1 & Pedicel & Extr. Fine & Globose & Uniform & Uniform & - & Very early & 10.1 \\
\hline 1 & Pedicel, calyx & Extr. Fine & Flat-globose & Variable & Variable & Medium & Early & 8.0 \\
\hline 1 & Pedicel & Extr. Fine & Ellipsoid-conical & Uniform & Uniform & Coarse & Early & 11.0 \\
\hline 1 & Calyx & Extr. Fine & Globose & Uniform & Uniform & Medium & Early & 16.7 \\
\hline - & - & - & - & - & - & - & - & - \\
\hline 5 & Pedicel & Extr. Fine & Globose-conical & Uniform & Uniform & - & Very early & 12.2 \\
\hline 1 & Pedicel & Extr. Fine & Globose-conical & Variable & Variable & Medium & Medium early & 11.4 \\
\hline 1 & Pedicel & Extr. Fine & Globose-conical & Variable & Variable & Medium & Early & 12.6 \\
\hline 10 & Pedicel & Extr. Fine & Conical & Variable & Variable & Coarse & Early & 13.3 \\
\hline 1 & Pedicel & Extr. Fine & Globose & Uniform & Uniform & Medium & Very early & 11.8 \\
\hline 5 & Pedicel & Med. Heavy & Globose-conical & Variable & Variable & Coarse & Early & 10.3 \\
\hline 0 & - & - & Flat-globose & Variable & Variable & Fine & Medium & 10.8 \\
\hline 5 & Pedicel & Extr. Fine & Globose & Variable & Uniform & Coarse & Medium early & 11.1 \\
\hline 5 & Pedicel & Extr. Fine & Globose & Variable & Variable & Coarse & - & 11.4 \\
\hline 2 & Pedicel, calyx & Med. Heavy & Oblong & Variable & Variable & Medium & - & 13.3 \\
\hline 1 & Pedicel & Extr. Fine & Globose & Variable & Variable & Medium & Early & 11.4 \\
\hline 2 & Pedicel & Extr. Fine & Globose-conical & Uniform & Variable & Fine & - & 12.0 \\
\hline 1 & Pedicel & Extr. Fine & Globose & Variable & Variable & Coarse & Very early & 11.2 \\
\hline 2 & Pedicel & Extr. Fine & Globose-conical & Variable & Variable & Medium & - & 11.0 \\
\hline 0 & None & None & Globose & Variable & Uniform & Coarse & Early & 11.8 \\
\hline 1 & Pedicel & Extr. Fine & Flat-globose & Variable & Uniform & Medium & Very early & 11.6 \\
\hline- & - & - & Globose & Uniform & Uniform & Medium & Very early & 12.7 \\
\hline - & - & - & - & & - & - & - & - \\
\hline - & Pedicel & Extr. Fine & Globose-conical & Uniform & Uniform & Medium & Very early & 11 \\
\hline 5 & Pedicel & Med. Heavy & Globose & Uniform & Uniform & Medium & Extremely early & 9.7 \\
\hline 1 & Pedicel & Extr. Fine & Globose & Uniform & Variable & Coarse & Early & 8.5 \\
\hline 2 & Pedicel & Extr. Fine & Globose & Variable & Variable & Coarse & - & 11.3 \\
\hline 20 & Entire fruit & Med. Heavy & Flat & Variable & Variable & Coarse & - & 13.1 \\
\hline 15 & Pedicel, calyx & Med. Heavy & Globose-conical & Variable & Variable & Medium & - & 14.1 \\
\hline - & - & - & - & - & - & - & - & - \\
\hline 1 & Pedicel & Extr. Fine & Conical & Variable & Variable & Medium & Early & 11.9 \\
\hline$<1$ & Pedicel & Extr. Fine & Globose & Variable & Uniform & Medium & - & 12.5 \\
\hline
\end{tabular}

This case example demonstrates the importance of having materials backed up at alternative field or storage conditions. Since the original 1995 and 1996 wild population orchards from Kazakhstan were planted in $1997,15 \%$ and $30 \%$ of the individuals within the populations from sites 6 and 9 , respectively, were lost before samples could be collected for DNA extraction in 2002. These trees were lost due to competition for resources from adjacent trees, disease infestation, and poor suitability to the PGRU field environment. Our core collections for site 6 and site 9 effectively captured the genetic diversity of the materials in the field from which DNA was collected. It was not possible to include $29 \%$ to $39 \%$ of the individuals for which DNA had been extracted, but $94 \%$ and $89 \%$ of the allelic diversity from sites 6 and 9 were captured in the respective core- 3 collections. Efforts are now under way to back-up the $M$. sieversii field collection as seeds. While some trees will be kept as clonal representatives in the main Malus collection and as cryo-stored, dormant buds (Forsline et al., 1999; Towill et al., 2004), many of the M. sieversii trees will be removed from the orchard setting and their genetic resources distributed as seeds. This lowers the maintenance costs of the PGRU Malus collection as a whole and supplements the original seed collected from these sites in 1995 and 1996 for some of the accessions (Table 1).

The core- 3 collections were validated to ensure that unique alleles contributed to the final core collection. The core- 3 collections of 35 individuals from each of sites 6 and 9 captured most of the allelic diversity and also represented the allelic frequencies within each population. Despite the inclusion of 12 maternal parents (of the half-sib families) in the site 9 analyses, only two of those parents were selected for inclusion in the core- 3 collection. This indicates that the maternal trees were not providing the bulk of the genetic diversity. Since $M$. sieversii is predominantly outcrossing, novel paternal genes were represented in the seedling accessions.

The site 6 and site 9 core- 3 collections have been described and validated. Storing these populations as seeds when phenotypic evaluations are completed is less expensive than maintaining field tree collections. In order to minimize the effects of self-incompatibility (which is not characterized in these populations) and maximize the efficiency of the fieldwork, the following method for seed production has been proposed.

As stated previously, two sets of genetically representative seeds will be produced, one each for the site 6 and site 9 populations. Trees originating from different populations will not be crossed.

For the first site, four pools of bulked pollen (A, B, C, and D) will be collected from an equal number of flowers from unique sets of either nine, nine, nine, or eight of the 35 core- 3 individuals. This eliminates some of the pollen competition that occurs if all the pollen is bulked, yet ensures that pollination will occur, even if some accessions share self-incompatibility alleles. Self-incompatibility has 
not been characterized in this species but may impact the efficacy of this crossing design. By assembling four pollen pools, the practical logistics of implementing the field crosses is achieved while any variance in male reproductive success is partitioned. The effective population size of the resulting seeds can vary from $\approx 14$ in the worst case scenario, where only one pollen parent per pool sires all the seeds, to 70 , where each pollen parent sires equal numbers of seeds. Self-incompatibility characterization is needed in this species.

The 35 core- 3 trees will also serve as females in the crossing design. All pollinated flowers will be emasculated, pollinated, and then bagged to prevent open pollination events. Twenty flowers from one branch of the first tree will be fertilized with pollen pool A. An additional 20 flowers will be fertilized with pollen pool $\mathrm{B}$, and likewise for pollen pools $\mathrm{C}$ and $\mathrm{D}$. Individual branches pollinated with different pollen pools will be labeled accordingly. The same procedure will be followed on each of the additional 34 trees. This process may need to be carried out in two successive years due to sparse flowering on some trees and/or poor fruit set after emasculation and pollination.

At harvest, the apples from each labeled branch of each tree will be kept separately from one another. Seeds will be removed from each of the 140 sets of apples ( 4 branches $\times 35$ trees). Then, four seeds will be removed from each of the 140 sets of apple seeds and pooled, resulting in a final pool size of 560 apple seeds. These seeds represent one replicate of the entire population and will be stored as a group. Additional replicates are collected and each replicate will be stored separately from the other replicates. Assuming that at least four seeds form within each apple, we expect that at least 20 replicate sets of pooled seeds will be created. These replicates could be used for distribution purposes as well as long term storage at the PGRU and USDA's National Center for Genetic Resources Preservation in Ft. Collins, Colo. Properly dried apple seeds (adjusted to $25 \%$ relative humidity) should theoretically store for many years at $-20{ }^{\circ} \mathrm{C}$ (Justice and Bass, 1978).

We have proposed a method to store field collections of vegetatively propagated plants as seeds. When field collections are fully characterized, it is more economical to preserve alleles present in these collections in seed form, rather than as field plants. Allelic diversity of field populations can be determined using molecular methods and neutral markers. Specific individuals that provide allelic richness in the population are selected for inclusion in core collections using a strategy that maximizes allelic richness. Once core collections are designated, seeds can be produced from the orchard collections and stored for distribution and future projects. This strategy could be applied to many other field collections of wild plant material in the NPGS.

\section{Literature Cited}

Bataillon, T.M., J.L. David, and D.J. Schoen. 1996. Neutral genetic markers and conservation genetics: Simulated germplasm collections. Genetics 144:409-417.

Clark, R.L., H.L. Shands, P.K. Bretting, and S.A. Eberhart. 1997. Managing large diverse germplasm collections. Crop Sci. 37:1-6.

Crossa, J., C.M. Hernandez, P. Bretting, S.A. Eberhart, and S. Taba. 1993. Statistical genetic considerations for maintaining germplasm collections. Theor. Appl. Genet. 86:673-678.

Dzhangaliev, A.D. 2003. The wild apple tree of Kazakhstan. Hort. Rev. 29:63-303.

Forsline, P.L. and H.S. Aldwinckle. 2004. Evaluation of Malus sieversii seedling populations for disease resistance and horticultural traits. EUCARPIA Symp. on Fruit Breeding and Genet.,1-5 Sept. 2003, Angers, France. Acta Hort. 663:529-534.
Forsline, P.L., H.S.Aldwinckle, E.E. Dickson, and S.C. Hokanson. 2003. Collection, maintenance, characterization, and utilization of wild apples from central Asia. Hort. Rev. 29:1-61.

Forsline, P.L., J.R. McFerson, W.F. Lamboy, and L.E. Towill. 1999. Development of base and active collections of Malus germplasm with cryopreserved dormant buds. Acta Hort. 484:75-78.

Goudet, J. 1995. FSTAT, a program for IBM PC compatibles to calculate Weir and Cockerham's (1984) estimators of F-statistics. J. Hered. $86: 485-486$

Gouesnard, B., T.M. Bataillon, G. Decoux, C. Rozale, D.J. Schoen, and J.L. David. 2001. MSTRAT: An algorithm for building germ plasm core collections by maximizing allelic or phenotypic richness. J. Hered. 92:93-94.

Harris, S.A., J.P. Robinson, and B.E. Juniper. 2002. Genetic clues to the origin of the apple. Trends in Genet. 18:426-430.

Hemmat, M., N.F. Weeden, and S.K. Brown. 2003. Mapping and evaluation of Malus $\times$ domestica microsatellites in apple and pear. J. Amer. Soc. Hort. Sci. 128:515-520.

Hokanson, S.C., W.F. Lamboy, A.K. Szewc-McFadden, and J.R. McFerson. 2001. Microsatellite (SSR) variation in a collection of Malus (apple) species and hybrids. Euphytica 118:281-294.

Hokanson, S.C., J.R. McFerson, P.L. Forsline, W.F. Lamboy, A.D. Djangaliev, and H.S. Aldwinckle. 1997. Collecting and managing wild Malus germplasm in its center of diversity. HortScience 32:173-176.

Hokanson, S.C., A.K. Szewc-McFadden, W.F. Lamboy, and J.R. McFersen. 1998. Microsatellite (SSR) markers reveal genetic identities, genetic diversity and relationships in a Malus $\times$ domestica borkh. core collection. Theor. Appl. Genet. 97:671-683.

Holbrook, C.C., W.F. Anderson, and R.N. Pittman. 1993. Selection of a core collection from the U.S. germplasm collection of peanut. Crop Sci. 33:859-861.

Justice, O.L. and L.N. Bass. 1978. Agriculture Handbook No. 506, Principles and practices of seed storage. U.S. Govt. Printing Office, Washington, D.C.

Lamboy, W.F. and C.G. Alpha. 1998. Using simple sequence repeats (SSRs) for DNA fingerprinting germplasm accessions of grape (Vitis L.) species. J. Amer. Soc. Hort. Sci. 123:182-188.

Lamboy, W.F., J. Yu, P.L. Forsline, and N.F. Weeden. 1996. Partitioning of allozyme diversity in wild populations of Malus sieversii $\mathrm{L}$. and implications for germplasm collection. J. Amer. Soc. Hort. Sci. 121:982-987.

Lewis, P.O. and D. Zaykin. 2001. GDA user's manual. Dept. of Ecol. and Evolutionary Biol., Univ. of Connecticut. 27 July 2004. <http://lewis. eeb.uconn.edu.lewishome>.

Luby, J., P. Forsline, H. Aldwinckle, V. Bus, and M. Giebel. 2001. Silk road apples - Collection, evaluation, and utilization of Malus sieversii from Central Asia. HortScience 36:225-231.

McKhann, H.I., C. Camilleri, A. Berard, T. Bataillon, J.L. David, X. Reboud, V. Le Corre, C. Caloustian, I.G. Gut, and D. Brunel. 2004. Nested core collections maximizing genetic diversity in Arabidopsis thaliana. Plant J. 38:193-202.

Petit, R.J., A.E. Mousadik, and O. Pons. 1998. Identifying populations for conservation on the basis of genetic markers. Conservation Biol. 12:844-855.

Schoen,D.J. and A.H.D. Brown. 1995. Maximising genetic diversity in core collections of wild relatives of crop species, p. 55-76. In: T. Hodgkin, A.H.D. Brown, Th.J.L. van Hintum, and E.A.V. Morales (eds.). Core collection of plant genetic resources. IPGRI, Wiley Sayce, Rome.

Skinner, D.Z., G.R. Bauchan, G. Auricht, and S. Hughes. 1999. Amethod for the efficient management and utilization of large germplasm collections. Crop Sci. 39:1237-1242.

Tohme, J., P. Jones, S. Beebe, and M. Iwanaga. 1995. The combined use of agroecological and chracteriztaion data to establish the CIAT Phaseolus vulgaris core collection, p. 95-107. In: T. Hodgkin, A.H.D. Brown, Th.J.L. van Hintum, and E.A.V. Morales (eds.). Core collection of plant genetic resources. IPGRI, Wiley Sayce, Rome, Italy.

Towill, L.E., P.L. Forsline, C. Walters, J. Waddell, and J. Laufman. 2004. Cryopreservation of Malus germplasm using a winter vegetative bud method: Results from 1915 accessions. Cryoletters (in press).

U.S. Department of Agriculture. 2004. National genetic resources program. Germplasm resources information network (GRIN). USDA, ARS Natl. Germplasm Resources Laboratory, Beltsville, Md. 27 July 2004. <http://www.ars-grin.gov/cgi-bin/npgs/html/>. 